\title{
El traje escénico en la Danza Española: importancia y simbolismo
}

Rosa María Suárez Muñoz

Universidad de Granada (España)

María del Mar Ortiz Camacho

Universidad de Granada (España)

Antonio Baena Extremera

Universidad de Granada (España) 



\title{
El traje escénico en la Danza Española: importancia y simbolismo
}

\section{Scenic costume in Spanish Dance: importance and symbolism}

\author{
Rosa María Suárez Muñoz \\ Universidad de Granada (España) \\ rsuarezdanza@gmail.com \\ María del Mar Ortiz Camacho \\ Universidad de Granada (España) \\ mmortiz@ugr.es
}

\author{
Antonio Baena Extremera \\ Universidad de Granada (España) \\ abaenaextrem@ugr.es
}

Fecha de recepción: 18 de octubre de 2018

Fecha de aceptación: 20 de octubre de 2018

\section{Resumen}

El vestuario teatral, en la génesis de un proyecto escénico de danza, se considera un elemento más cuya importancia radica en su significación. El objetivo general de este trabajo ha sido constatar la importancia del traje escénico como herramienta transmisora de conceptos y como elemento simbólico que aporta un sentido a la interpretación de la Danza Española. Se ha estudiado el uso de este vestuario desde una perspectiva profesional (Ballet Nacional de España (BNE), intérpretes y coreógrafos de reconocido prestigio) y desde una perspectiva educativa (Conservatorios Profesionales de Danza de Andalucía-España (CPDA)). Se ha realizado una triangulación metodológica combinando investigación cuantitativa y cualitativa utilizando como instrumentos básicos el cuestionario y entrevistas previamente validadas. Como conclusión, resalta la importancia otorgada al uso del vestuario teatral en la Danza Española como herramienta comunicativa intencional, así como su aportación a la interpretación en la representación escénica, confirmándose así las hipótesis planteadas.

Palabras clave: Danza española; Indumentaria; Vestuario teatral; Ballet Nacional de España; Conservatorio Profesional de Danza. 


\begin{abstract}
The theatrical costumes, in the genesis of a scenic dance project, are considered one more element whose importance lies in its significance. The aim of this paper has been to verify the importance of it as a communicating tool of concepts and as a symbolic element that contributes a sense to the interpretation of Spanish Dance. The use of this costume has been studied from a professional perspective (National Ballet of Spain (BNE), renowned performers and choreographers) and from an educational perspective (Professional Dance Conservatories of Andalusia (Spain) (CPDA)), making a methodological triangulation that combines quantitative and qualitative research, using the questionnaire and previously validated interviews as basic instruments. As a conclusion, the importance given to the use of theatrical costumes in Spanish Dance as an intentional communicative tool stands out, as well as their contribution to the interpretation in the scenic representation, confirming the hypotheses raised.
\end{abstract}

Keywords: Spanish Dance; Dress, Theatrical Costumes; National Ballet of Spain; Professional Dance Conservatory.

\title{
1. INTRODUCGIÓN
}

En el análisis semiótico de una representación de danza, el vestuario teatral atesora la potestad de aportar información respecto al concepto que se quiere transmitir, convirtiéndose en un elemento escénico comunicativo. Se parte de esta premisa para articular su significado simbólico en el contexto escénico, adoptándose como referencia la definición de semiótica ofrecida por Eco como "la ciencia que estudia todos los procesos culturales como actos de comunicación" (Eco, 1986, p. 69).

En este trabajo se pretende poner de manifiesto que el vestuario escénico transmite conceptos, como parte de la comunicación no verbal intrínseca a la imagen escénica de los espectáculos de danza. Hollander (citado por Sánchez-Contador, 2016, p. 134) afirma que "las prendas son objetos hechos de tela que transmiten mensajes, cuyo poder va más allá que el mensaje que transmiten las prendas en sí mismas". Igualmente se hace necesario resaltar la importancia que el vestuario sostiene dentro de la Danza Española, en particular, como portador de un contenido simbólico, cultural e identitario.

La Danza Española es una especialidad de danza de una gran complejidad técnica, ya que engloba cuatros estilos de danza diferenciados entre sí, como son: la Escuela Bolera, el Folclore, el Flamenco y la Danza Estilizada. Cada una de estas disciplinas tiene sus propias características que la identifican. "El conjunto de estas realidades forma lo que hoy en día conocemos como Danza Española, con un vocabulario específico para cada una de las materias que la componen, que exige una especial versatilidad para su interpretación" (BOE N 306,1997 , pp. 37.60737.608). Se hace necesario dotar a cada estilo de rasgos propios y, para ello, resulta imprescindible el vestuario escénico, ya que es uno de los instrumentos de los que se 
puede valer el espectador para identificar los diferentes estilos de la Danza Española. La indumentaria elegida nos lleva a discernir sobre el estilo de danza, la zona de España a la que pertenece o la época en la que se contextualiza.

Se trata de una disciplina de gran riqueza técnica y estilística, única en el mundo y genuinamente ligada al sentir popular y a la identidad de España. Como afirma Marrero: "La danza española es, ante todo, danza, con esto quiero decir que se danza, ante todo, por una convicción vital" (Marrero, 1959, p. 24). Este autor defiende que la Danza Española proviene de las más hondas raíces del ser humano ya que está íntimamente ligada a la vida. En la misma línea, Bonilla mantiene que "la danza española, cuando se ha orientado hacia el ballet, puede dotarlo, en su riqueza de ideas, de un vigor expresivo, de ese vigor auténticamente hispano, a veces casi ascético, sin desorbitarlo ni convertirlo en tópico" (Bonilla, 1964, p. 320). Recientemente Arranz del Barrio manifiesta, respecto a la labor del coreógrafo de Danza Española, que "se trata de diseñar, configurar y significar la danza, ya que, el componente coreográfico viene dado por la tradición. Esta manera de obrar implica una acción singular, característica de identidad del baile español [...] (Arranz del Barrio, 2016, p. 108).

En el contexto de la Danza Española el vestuario escénico es un hecho simbólico social y cultural que se integra en el imaginario español, y se presenta como una proyección de la identidad y cultura de este país. Algunos de los trajes que se usan en la Danza Española, se pueden considerar patrimonio cultural. Este es el caso del traje de Flamenca, que se erige como el traje tradicional andaluz si se tiene en cuenta la definición que realiza Martínez de la Indumentaria Flamenca como bien etnológico:

Puesto que cumple las condiciones generalmente exigibles a los Bienes Culturales (es el producto material o inmaterial de una sociedad determinada y es portador de un contenido simbólico identitario que la comunidad reconoce como suyo) forma parte, por tanto, del Patrimonio Etnológico Andaluz: en primer lugar, por su procedencia artesanal y la supervivencia de unas técnicas de elaboración artesanales, sucesivamente perfeccionadas en el transcurso del tiempo, y con unas formas específicas de transmisión de saberes en el seno de una comunidad y en segundo término, por su contenido simbólico representativo de identidad [...] (Martínez, 2009, p. 117).

Este hecho se puede extrapolar a otros trajes tradicionales de diferentes regiones de España que también son portadores de estas características identificativas.

La presente investigación se afronta desde una perspectiva holista recogiéndose datos cualitativos y cuantitativos de diferentes fuentes. De esta forma, se aborda el tema del vestuario escénico desde dos ámbitos de la danza: el profesional y el amateur o integrado en la formación.

Por un lado, se elige para esta investigación al Ballet Nacional de España (BNE) como máximo representante de la Danza Española dentro y fuera de este país. 
Teniendo en cuenta que el vestuario escénico forma parte de la historia del BNE, se considera que la investigación en este campo podría contribuir al conocimiento y difusión de esta manifestación artística respaldada en España por el Instituto Nacional de Artes Escénicas y Música (INAEM), dependiente del Ministerio de Cultura y Deporte. El BNE nació en 1978, en aquel momento la Dirección General de Teatro y Espectáculos del Ministerio de Cultura creó las Compañías Nacionales de Danza: Danza Española y Clásica. En un principio, D. Antonio Gades asumió la dirección del BNE bajo el nombre de Ballet Nacional Español (Ministerio de Educación Cultura y Deporte, 2003). Desde septiembre de 2011 está dirigido por D. Antonio Najarro. El BNE tiene un repertorio coreográfico, hasta abril de 2018, de 118 producciones, 4689 trajes, 21.197 prendas y 2.462 pares de zapatos. Para la conservación y organización de este vestuario se creó en 1998 la sección "Regiduría de Vestuario", que depende del Departamento de Producción y cuenta con la colaboración de la sección de Sastrería. Hasta entonces, los fondos de vestuario del BNE se almacenaban sin un criterio específico, por lo que era necesario catalogar e informatizar estas piezas. El objetivo de la sección de Regiduría de Vestuario fue adaptar los protocolos de actuación de los museos, que estaban dotados de fondos de vestuario, a los almacenes del BNE. Estas dependencias guardan la memoria de los espectáculos a través de un vestuario que debería considerarse patrimonio cultural y que, algún día, podría exponerse en un museo (García, 2009).

Por otro lado, se busca información en el ámbito de la educación en danza, concretamente en los Conservatorios Profesionales de Danza de Andalucía (CPDA). Se ha comparado el uso del vestuario escénico en este contexto (asignatura de "Talleres Coreográficos") y en el BNE. El motivo que nos conduce a elegir esta asignatura para establecer un paralelismo con el BNE, respecto a la expresividad y el simbolismo del uso del vestuario teatral, es que, en la misma, se elaboran proyectos escénicos que se interpretan en público. Esto hace, al igual que en el BNE, que el vestuario tenga un tratamiento específico como elemento necesario para expresar conceptos. Esta asignatura se imparte en los seis cursos de las Enseñanzas Profesionales de Danza, en los seis CPDA. En ambos casos existen similitudes conceptuales y la necesidad de poner en valor este instrumento que ensalza la expresividad del lenguaje corporal y la interpretación en las representaciones escénicas de toda índole, bien sean realizadas por profesionales o por estudiantes de danza.

Una vez contextualizada esta investigación, se establecen las siguientes hipótesis:

1. El uso del vestuario teatral se considera un elemento más de la escenografía por parte de los distintos colectivos implicados en la puesta en escena de proyectos coreográficos en la Danza Española. Su importancia radica en su capacidad de expresión y comunicación.

2. El uso del vestuario escénico facilita la interpretación del personaje al dotarlo de significado. 
A partir de estas hipótesis los objetivos de esta investigación son:

1. Constatar la importancia del vestuario teatral en la puesta en escena de la Danza Española como elemento de comunicación.

2. Comprender la simbología del vestuario en escena: aportación a la interpretación de la danza.

\section{METODOLOGÍA}

\subsection{Muestra}

Según Sierra "la muestra se puede definir como una parte de un conjunto o población debidamente elegida, que se somete a observación científica en representación del conjunto, con el propósito de obtener resultados válidos también para el universo total investigado" (Sierra, 2007, p. 364).

Para esta investigación se ha utilizado un diseño muestral no probabilístico y por conveniencia según el número de casos disponibles a los que se ha podido acceder. Además de ello, se han usado casos críticos en la selección de la muestra para las entrevistas. La información necesaria para esta investigación se ha obtenido a través de diferentes fuentes como ya se ha indicado.

Para la investigación cuantitativa se seleccionaron dos tipos de muestras: los bailarines del BNE en la temporada 2016/2017, y el profesorado de los CPDA en el curso escolar 2016/2017. En el caso del BNE, en septiembre de 2017, lo componían 40 integrantes entre bailarines de cuerpo de baile, bailarines solistas y primeros bailarines, de los cuáles 23 participaron en esta investigación (11 bailarines y 12 bailarinas). Respecto al profesorado-CPDA, la muestra seleccionada fue representativa del universo, de tal forma que, siendo el número de la población de 126 profesores que impartían la asignatura de Talleres Coreográficos en las distintas Especialidades de Danza, se calculó el tamaño de la muestra, teniendo en cuenta un margen de error del 10\% y un nivel de confianza del $90 \%$. El tamaño de la muestra correspondía a un mínimo de 45 profesores, siendo nuestra muestra final de 49 , que son los que respondieron a la encuesta (43 profesoras y 6 profesores).

Por otro lado, para la investigación cualitativa, se realizó un muestreo no probabilístico por el que se seleccionaron personas relacionadas con el tema objeto de estudio que aportaron información significativa. Su elección se orientó a coreógrafos y bailarines de reconocido prestigio, como son:

- D. Antonio Najarro, director del BNE, coreógrafo e intérprete.

- D. Antonio Canales, ex bailarín del BNE, Premio Nacional de Danza 1995, coreógrafo e intérprete. 
- $\mathrm{D}^{\mathrm{a}}$. Pacita Tomás, bailarina de reconocida trayectoria artística y representante de la Danza Española anterior a la creación del BNE.

- D. Juan Mata, ex bailarín del BNE, coreógrafo e intérprete.

- D. Rubén Olmo, ex bailarín del BNE, Premio Nacional de Danza 2015, coreógrafo e intérprete.

\subsection{Diseño}

El diseño del presente trabajo de investigación ha sido de carácter no experimental, seccional, descriptivo e inferencial (Sierra, 2001).

Respecto a la metodología utilizada se ha realizado una triangulación metodológica la cual es definida por Denzín "como la aplicación y combinación de varias metodologías de la investigación en el estudio de un mismo fenómeno" (Denzín, 1970, p. 297). Se utiliza, por tanto, metodología cuantitativa y cualitativa, realizando una triangulación de los resultados desde diferentes puntos de vista. De esta forma se profundiza en el objeto de estudio mejorando su comprensión. La recogida de datos se realiza mediante la observación directa, cuestionarios, entrevistas y análisis de documentación.

\subsection{Instrumentos}

Para la consecución de los objetivos propuestos en este trabajo, se ha utilizado la observación documental y la observación mediante encuesta, en la que se ha empleado como instrumento básico el cuestionario, así como determinadas entrevistas.

\section{Observación documental}

Los documentos consultados para este trabajo han sido del área de danza en general, del teatro, la historia del arte, la antropología y la Danza Española.

\section{Observación mediante encuesta}

El tipo de cuestionario utilizado en este estudio fue el cuestionario simple, puesto que los encuestados respondían por escrito, sin intervención directa de los responsables de la investigación. Estos sí intervenían en las entrevistas.

Se diseñó un cuestionario para pasar a todo el elenco del BNE con el fin de conocer su percepción respecto a la importancia que conceden al uso del vestuario escénico. Este instrumento presentó 47 ítems que medían las sensaciones que experimentaban al usar el mismo. Las respuestas se recogían en escala tipo Likert desde 1 hasta 5, que iban de Nada a Mucho y de Ninguna dificultad a Extrema Dificultad, en su mayoría, aunque se facilitaron otros tipos de respuestas. 
Se diseñó otro cuestionario para el profesorado-CPDA de las distintas Especialidades de Danza, con el fin de valorar sus apreciaciones acerca de la importancia del vestuario en la génesis de la obra, como hecho simbólico, y en la interpretación de la misma. En este caso constaba de 24 ítems con respuestas que se recogían en escala tipo Likert desde 1 hasta 5, que iban de Nada a Mucho y de En ninguna ocasión a En muchas ocasiones. Igualmente tenía cuatro preguntas abiertas completando un total de 28 ítems.

Ambos cuestionarios y dos tipos de entrevistas, fueron validados previamente. Para llevar a cabo la validación de estos instrumentos, se consultó a cinco expertos en diseño y validación de cuestionarios, seleccionados por su significativa experiencia profesional y formación académica, así como por su accesibilidad. Se les facilitó los dos tipos de cuestionarios y los dos tipos de entrevistas realizados expresamente para esta investigación. Además de ello, se les proporcionó una hoja de respuestas donde debían ir señalando de cada ítem la univocidad, pertinencia e importancia y las observaciones que estimaran oportunas. Una vez rellena la hoja de respuestas por cada experto, se llevaron a cabo los análisis estadísticos mediante el Programa SPSS v.22. Para ello, se calculó el Coeficiente de Correlación Intraclase (CCI), evaluando la concordancia global de los cinco expertos sobre la univocidad, pertinencia e importancia de los ítems, a partir de un modelo de efectos mixtos y asumiendo una definición de acuerdo absoluto. Se obtuvieron resultados satisfactorios tanto en el análisis del rango intercuartílico, como en el coeficiente de correlación intraclase en pertinencia, importancia y univocidad de cada uno de los ítems. Los valores obtenidos se presentan en la Tabla 1.

Tabla 1. Resultados del CCI sobre 5 expertos

\begin{tabular}{lcccc}
\hline & $\begin{array}{c}\text { CUESTIONARIO } \\
\text { BAILARINES BNE }\end{array}$ & $\begin{array}{c}\text { CUESTIONARIO } \\
\text { PROFESORADO CPDA }\end{array}$ & $\begin{array}{c}\text { ENTREVISTA } \\
\text { COREÓGRAFOS }\end{array}$ & $\begin{array}{c}\text { ENTREVISTA BAILARINES } \\
\text { ANTERIORES BNE }\end{array}$ \\
\hline IMPORTANCIA & 0.827 & 0.634 & 0.61 & 0.655 \\
\hline PERTINENCIA & 0.707 & 0.527 & 0.412 & 1 \\
\hline UNIVOCIDAD & 0.796 & 0.48 & 0.909 & 1 \\
\hline
\end{tabular}

Además, para medir la dispersión en el acuerdo de los jueces, se utilizó como criterio el recorrido intercuartílico. Como resultado final, se revisaron 2 ítems y se reformularon, atendiendo a las sugerencias de los expertos. Las correcciones fueron mínimas.

\subsection{Procedimiento}

La presentación de los cuestionarios a los participantes iba precedida de un texto introductorio en el que se informaba del objeto de estudio, de la participación 
voluntaria de los encuestados y del tratamiento confidencial de sus respuestas. También se pedía máxima sinceridad y se resaltaba el anonimato del cuestionario. Para todo ello, se siguieron las recomendaciones de cumplimiento de los derechos de los encuestados en base a la Declaración de Helsinki (2013).

En el caso de las entrevistas, prevalecía un consentimiento informado que cada entrevistado debía firmar. En él se describía el objeto de estudio y se indicaba que los datos obtenidos a través de la entrevista se utilizarían exclusivamente para la investigación, o publicaciones relacionadas con la misma, y siempre bajo su autorización.

Respecto al diseño de los cuestionarios se siguieron una serie de pasos. En primer lugar, se hizo una revisión de documentación y cuestionarios de temas afines al objeto de estudio. A continuación, se validó el cuestionario por cinco expertos y se elaboró el cuestionario definitivo. Una vez finalizado el cuestionario, se envió al profesoradoCPDA y a los bailarines-BNE a través de la plataforma Google Forms. Finalmente se analizaron los datos con el programa SPSSv.22 y se elaboraron las conclusiones.

En cuanto a las entrevistas, en un primer momento se hizo una revisión bibliográfica y se elaboraron teniendo en cuenta las variables y los objetivos de la investigación. A continuación, se validaron por cinco expertos en diseño de cuestionarios, se realizaron registrándose en grabaciones de audio y posteriormente se transcribieron. Finalmente se analizaron y codificaron los datos a través del programa NVIVO 10 y se elaboraron las conclusiones.

\subsection{Análisis de los datos}

\subsubsection{Análisis metodología cuantitativa}

Para empezar, se llevó a cabo un análisis estadístico descriptivo de las variables mediante un análisis de frecuencia. A continuación se hizo un análisis inferencial para constatar el grado de asociación/relación entre variables nominales y/o ordinales $\mathrm{y}$, para ello, se elaboraron tablas de contingencia y se usaron pruebas de contraste con $x 2$. Asimismo, se llevó a cabo un análisis de correlaciones bivariadas mediante el coeficiente de correlación de Pearson, el cual nos permitiría determinar si dos variables se relacionaban entre sí, si esta relación era fuerte o débil, y qué dirección llevaría la misma. Cuando no se obtuvo significatividad en las correlaciones, se realizó la prueba d de Somers para comprobar si existían diferencias significativas entre las variables.

\subsubsection{Análisis metodología cualitativa}

El procedimiento que se utilizó para analizar las entrevistas y las preguntas abiertas de los cuestionarios fue una codificación abierta ("in vivo") en el software 
NVIVO 10. Este programa permite organizar y analizar datos no estructurados como entrevistas, documentos, imágenes, videos, etc.

\section{Transcripciones de las entrevistas}

Se realizaron grabaciones digitales de las entrevistas en condiciones óptimas para la captación clara de las voces de entrevistado y entrevistador. Posteriormente se transcribieron las entrevistas de forma literal, de esta manera se traspasó la información a texto para facilitar el análisis de los datos obtenidos. Se cotejaron varias veces los resultados con los audios originales, rectificando posibles errores hasta obtener la transcripción exacta. Por último, se importaron las entrevistas al software NVIVO 10 dentro del apartado Recursos como Elementos Internos.

En el caso de las preguntas abiertas de los cuestionarios, éstas se cumplimentaron en el software de productividad Google Docs a través del cuestionario correspondiente. Las respuestas se exportaron en un archivo de Excel, y éste se importó al Software NVIVO 10. A continuación, se realizó una codificación automática para crear los casos de los participantes.

\section{Participantes}

Respetando el anonimato de los participantes, a cada uno se le atribuyó un nombre ficticio con el fin de identificarlos en el procesamiento de la información. De esta forma, se crearon nodos de casos para representar a los participantes en las encuestas, tanto a los integrantes del BNE como al profesorado-CPDA, y se les asignaron atributos de género, edad y experiencia profesional.

\section{Proceso de análisis de las entrevistas y las preguntas abiertas}

Se realizó una codificación abierta en el software NVIVO 10, identificando las ideas y conceptos más significativos relacionados con nuestros objetivos. Para ello, se nombró cada categoría y se etiquetó cada fragmento de la información con un nombre representativo del contenido del mensaje (Campo-Redondo y Labarca, 2009). Después se realizó una categorización axial organizando los datos e identificando las categorías centrales que serían el objeto principal de nuestro análisis y se procedió a definirlas utilizando una metodología inductiva y deductiva. Finalmente se creó una estructura jerárquica, o árbol de nodos, con sus correspondientes categorías y subcategorías. En este caso se definieron los nodos en los que se ramificaban todas las categorías identificadas. A continuación, se codificó toda la literatura importada al software en el árbol de categorías, así como algunas imágenes relativas al contenido investigado. Finalmente, se realizó una consulta de frecuencia de palabras a partir del nodo Importancia de vestuario para el objetivo 1.

\section{ANÁLISIS DE RESULTADOS}

A continuación, se detallan los resultados organizados por objetivos de este trabajo de investigación. 
El traje escénico en la Danza Española.... - R.M. Suárez Muñoz y otros

Objetivo 1. Constatar la importancia del vestuario teatral en la puesta en escena de la Danza Española como elemento de comunicación

\section{Cuestionario para profesorado-CPDA}

\section{A) Análisis descriptivo}

Se calcularon los estadísticos descriptivos de la variable Importancia del vestuario y para las subdimensiones de esta variable se detectaron valores muy altos $(\mathrm{M}=4.80 ; \mathrm{DT}=0.407)$. En cuanto a la desviación típica cabe decir que, teniendo en cuenta las puntuaciones mínimas y máximas que pueden alcanzar las tres subdimensiones, se observó que los distintos valores de la distribución se encontraban próximos entre sí, por lo que presentaron poca dispersión o variabilidad (ver Tabla 2).

Tabla 2. Estadísticos descriptivos importancia vestuario para profesorado-CPDA. Diferencias por géneros

\begin{tabular}{lccccc}
\hline & N & Mínimo & Máximo & Media & Desviación estándar \\
\hline Importancia vestuario & 49 & 4 & 5 & 4.80 & 0.407 \\
Importancia vestuario Masculino & 6 & 5 & 5 & 5.00 & 0.000 \\
Importancia vestuario Femenino & 43 & 4 & 5 & 4.77 & 0.427 \\
\hline
\end{tabular}

En cuanto a la pregunta "Como docente $¿$ considero que el vestuario es importante a la hora de bailar?", los resultados mostraron que en una escala Likert con 5 niveles de valoración respecto a la variable importancia del vestuario escénico (de 1/Nada a $5 / M u c h o$ ), un $20.4 \%$ del profesorado-CPDA respondió el nivel 4 (Bastante), y un 79.6\% el nivel 5 (Mucho).

El profesorado-CPDA otorga un papel relevante al vestuario en la puesta en escena de las obras coreográficas considerándolo Bastante o Muy Importante en las mismas (ver Tabla 3).

Tabla 3. Distribución de frecuencias de la importancia de vestuario para profesorado-CPDA

\begin{tabular}{lcc}
\hline & $\mathrm{N}$ & $\%$ \\
\hline Nada & 0 & 0.0 \\
Poco & 0 & 0.0 \\
Algo & 0 & 0.0 \\
Bastante & 10 & 20.4 \\
\hline Mucho & 39 & 79.6 \\
\hline Total & 49 & 100.0 \\
\hline
\end{tabular}

B) Análisis inferencial

Se analizó la relación entre las variables género del profesorado-CPDA y la importancia que se da al vestuario en la danza, mediante el análisis de tablas cruzadas. 
En el caso femenino, 33 profesoras de las 43 encuestadas, opinaron que el vestuario es Muy Importante (Mucho). Esta misma valoración la otorgó todo el profesorado de género masculino, un total de 6 . Cabe destacar que ningún encuestado consideró que el vestuario fuera Nada, Poco o Algo importante. Por tanto, los resultados aparecieron próximos entre sí, determinando que no existía relación entre estas variables. Las pruebas de Chi cuadrado mostraron un $\mathrm{p}<.185$ donde 2 casillas $(50.0 \%)$ tenían un recuento menor que $5 \mathrm{y}$ la frecuencia mínima esperada era de 1.22 . Teniendo en cuenta estos datos no se podía admitir que existieran diferencias significativas entre ambas variables, por lo que ambas eran independientes.

A continuación se realizó un análisis de correlaciones bivariadas entre las variables experiencia del profesorado e importancia que se otorga al vestuario en la puesta en escena, mediante el coeficiente de correlación de Pearson. Los resultados mostraron que la significatividad era .768, por lo que no había asociación entre ambas. Posteriormente se realizó la d de Somers y se comprobó que igualmente no existían diferencias significativas entre una variable y la otra, al mostrar una significatividad de .774 , por lo tanto, mayor que 0.05 .

\section{Cuestionario para bailarines- BNE}

C) Análisis descriptivo

Se calcularon los estadísticos descriptivos de la variable importancia del vestuario y para las subdimensiones de esta variable se detectaron puntuaciones altas $(M=4.74 ; D T=0.449)$. En cuanto a la desviación típica cabe decir que, teniendo en cuenta las puntuaciones mínimas y máximas que pueden alcanzar los tres subdimensiones, se observó que los distintos valores de la distribución se encontraban próximos entre sí, por lo que presentaban poca dispersión o variabilidad (ver Tabla 4).

Tabla 4. Estadísticos descriptivos importancia vestuario para bailarines-BNE, y diferenciación por géneros

\begin{tabular}{lccccc}
\hline & $\mathrm{N}$ & Mínimo & Máximo & Media & Desviación estándar \\
\hline Importancia vestuario & 23 & 4 & 5 & 4.74 & 0.449 \\
Importancia vestuario masculino & 11 & 4 & 5 & 4.64 & 0.505 \\
Importancia vestuario femenino & 12 & 4 & 5 & 4.83 & 0.389 \\
\hline
\end{tabular}

A continuación se expuso la frecuencia de esta variable. Respecto a la pregunta "¿Considero que el vestuario es importante para bailar?, en una escala Likert con 5 niveles de valoración (de 1/Nada a 5/Mucho), un $26.1 \%$ de los bailarines-BNE respondió el nivel 4 y un $73.9 \%$ el nivel 5 (ver Tabla 5). 
El traje escénico en la Danza Española.... - R.M. Suárez Muñoz y otros

Tabla 5. Distribución de frecuencias de la importancia de vestuario para bailarines-BNE

\begin{tabular}{lcc}
\hline & N & $\%$ \\
\hline Nada & 0 & 0.0 \\
Poco & 0 & 0.0 \\
Algo & 0 & 0.0 \\
Bastante & 6 & 26.1 \\
\hline Mucho & 17 & 73.9 \\
\hline Total & 23 & 100.0 \\
\hline
\end{tabular}

Se observa por tanto que, para los bailarines-BNE el vestuario en la puesta en escena de las obras coreográficas es Bastante o Muy importante.

D) Análisis inferencial.

A continuación se relacionaron las variables género de los bailarines- BNE e importancia del vestuario, mediante un análisis de tablas cruzadas. En el caso femenino, 10 de las 12 bailarinas encuestadas consideraron que el vestuario era Muy Importante, y en el caso masculino, 7 de los 11 bailarines encuestados tuvieron la misma opinión. Ningún encuestado contestó que el vestuario fuera Nada, Poco o Algo importante. Los resultados fueron próximos entre sí, determinando que no existía relación entre estas variables. Las pruebas de Chi cuadrado mostraron un $\mathrm{p}<.283$ donde dos casillas $(50.0 \%)$ tenían un recuento menor que 5 y la frecuencia mínima esperada era de 2.87 , por tanto, no se podía admitir que existieran diferencias significativas entre ambas variables, por lo que ambas eran independientes.

Por último, se realizó un análisis de correlaciones bivariadas mediante el coeficiente de correlación de Pearson entre las variables experiencia de los Bailarines$B N E$ y la importancia que dan al vestuario en la danza. Los resultados mostraron que la significatividad era 0.635 , por tanto, no había asociación entre ambas. Se procedió a realizar la d de Somers y al analizar los resultados, se observó queno existían diferencias significativas entre las variables, al mostrar una significatividad de 0.894 (p.> 0.05).

Tanto en el caso del profesorado-CPDA y en el de los bailarines-BNE, se otorgó una gran importancia al uso del vestuario escénico y, en ambos casos, el género y la experiencia profesional no determinaron la orientación de las respuestas, al ser variables independientes.

\section{Entrevistas y preguntas abiertas}

Respecto a la importancia del vestuario en el contexto de la obra coreográfica, se obtuvieron 23 referencias en el análisis realizado a través del software NVIVO 10 , procedentes de las preguntas abiertas de los cuestionarios a BailarinesBNE y Profesorado-CPDA, así como de las entrevistas realizadas a corógrafos y personalidades de la danza. 
A) Resultados en las preguntas abiertas

En las referencias que hacen los encuestados al tema de la importancia del vestuario en las representaciones escénicas se puede constatar cómo, de forma unánime, se otorgó una gran importancia al mismo, ratificando los resultados cuantitativos.

\section{Profesorado-CPDA}

Ante la pregunta abierta "Como docente de la asignatura Talleres Coreográficos ¿considero que el vestuario es importante en las representaciones de danza?", los siguientes encuestados coincidieron en su gran importancia, como se infiere de las referencias obtenidas:

- Luna (2017) "El papel del vestuario en la danza española es fundamental".

- Ruth (2017) "El vestuario es fundamental en la Danza Española y el Baile Flamenco".

- Belén (2017) "Considero muy importante un vestuario cuidado en cualquier coreografía".

- Rita (2017) "El vestuario ocupa un lugar importantísimo dentro de la danza".

- Sara (2017) "El vestuario es un elemento escénico más como pueden ser la escenografía, el diseño de iluminación, la música y el propio movimiento, entre otros. Todos esos elementos aportan a la obra su identidad global".

- Paz (2017) "Lo creo fundamental para una buena puesta en escena".

- Estrella (2017) "Creo que es muy importante que el alumnado tenga conciencia del papel que tiene un vestuario escénico. El vestuario es fundamental para la Danza Española".

- Berta (2017) "El vestuario es muy importante para la interpretación de la Danza Española".

- Celia (2017) "Es fundamental porque el vestuario y la escenografía completan la obra".

- Inés (2017) "Un buen vestuario finaliza un trabajo coreográfico".

- Maca (2017) "En mi opinión creo que es realmente importante cuidar la puesta en escena a través de su indumentaria, caracterización, atrezo, etc. por supuesto sin olvidarnos nunca del contenido".

\section{Bailarines-BNE}

- Lucas (2017) "El vestuario toma un papel muy relevante, tanto como la danza". 
B) Resultados en las entrevistas

En las 5 entrevistas realizadas se formuló a todos los coreógrafos y personalidades de la danza, la siguiente pregunta: "¿Qué importancia le concede al vestuario en su obra?", las respuestas seguían la misma línea que el profesorado-CPDA y bailarines- BNE, considerando fundamental su aportación, como se muestra en las sucesivas referencias:

- Najarro (2017): Le doy una importancia total al vestuario. Antes de crear la coreografía ya estoy visualizando cómo tiene que ir vestida. En muchas ocasiones monto movimientos acorde a cómo van a ir vestidos. Monto brazos, etc. acorde a cómo vestirán. Si en las chicas los vestidos van a ser con menos volúmenes, yo ya estoy pensando que a nivel de brazos van a llevar mucho más movimiento, si va a llevar mucho volumen el vestido o va a tener mucho vuelo, ya estoy pensando que van a llevar menos brazos porque van a estar moviendo tejidos, todo eso lo tengo en cuenta en muchas ocasiones antes de montar la coreografía. Generalmente se hace al revés, tú creas la coreografía y luego piensas en el vestuario, pero para mí es tan importante el vestuario, que va ligado a la idea que tú tienes, que es lo primero que te he dicho en un montaje coreográfico.-

- Canales (2016): Yo creo que todo, el vestuario, la escenografía, las luces, todo tiene su importancia. Una coreografía bella pero mal vestida o mal iluminada, pues no, pierde muchísimo. Yo creo que el vestuario tiene mucha importancia, la misma importancia que la iluminación.

- Mata (2017) "El vestuario es muy importante, sobre todo si se piensa en qué hay que bailar".

- Tomás (2017) “Doy mucha importancia al vestuario".-Olmo (2017): Pues de las cosas más importantes, yo creo que lo primero que se te pasa por la cabeza en una pieza, y más en danza, es una imagen, y una imagen no te la da la danza, la imagen primera te la da prácticamente la luz y el vestuario, para mí es muy importante que la gente salga bien vestida, si es algo histórico que siga unas fórmulas, una reglas, que aunque te lo lleves a la vanguardia, pero que la base principal esté, contextualizado en la época, aunque le quieras dar un punto más actual, pero que por lo menos, eso esté ahí [...] La parte de vestuario en mis ballets tiene mucha importancia, me gusta mucho ver a la gente bien vestida, no solo dentro de los ballets y del teatro, sino dentro de un tablao, de una sala alternativa...que la gente le de esa importancia.

Para finalizar, se realizó una consulta de frecuencia de palabras a partir del nodo Importancia de vestuario, obteniéndose resultados que enfatizan la idea general de la relevancia del vestuario en la obra coreográfica, siendo la palabra importante (con un conteo de 15) el adjetivo más utilizado respecto al sustantivo vestuario, seguido de la palabra importancia (con un conteo de 11), (véase Figura 1). 


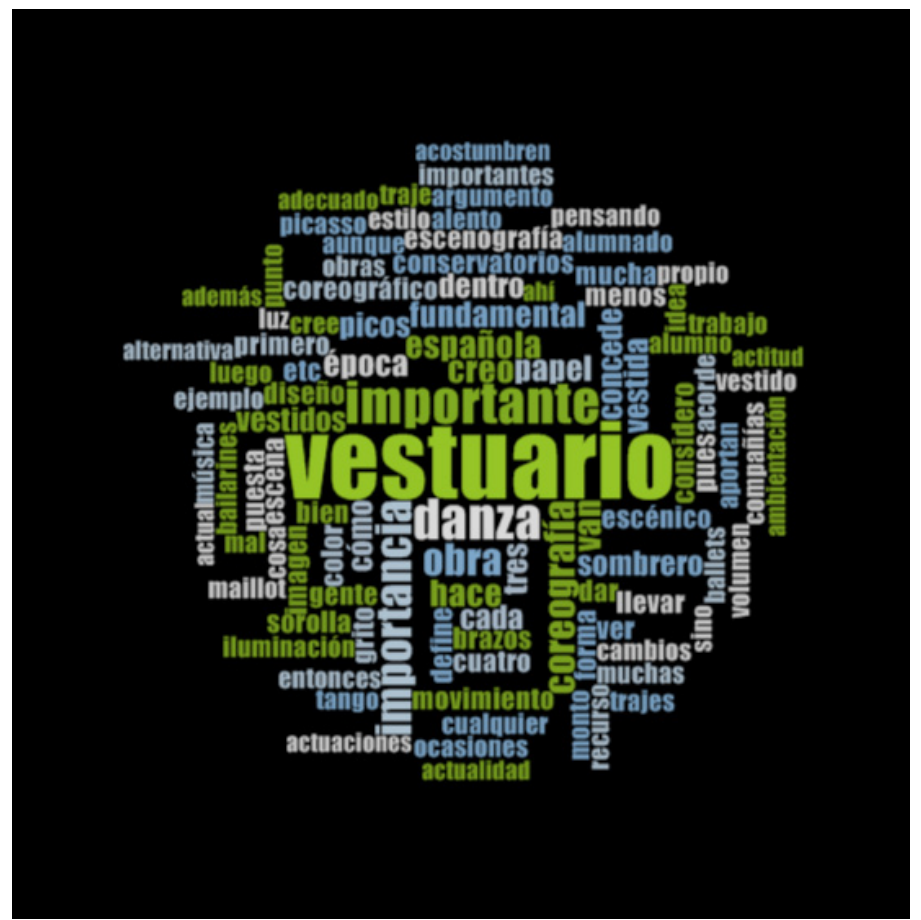

Figura 1. Marca de nube respecto a la consulta de frecuencia de palabras en cuanto al nodo importancia del vestuario. Fuente: Elaboración propia en NVIVO 10.

Objetivo 2. Comprender la simbología del vestuario en escena: aportación a la interpretación de la danza.

Cuestionario para profesorado- CPDA

A) Análisis descriptivo

Se calcularon los estadísticos descriptivos de la variable contribución del vestuario escénico a la interpretación de la danza y para las subdimensiones de esta variable se observaron puntuaciones altas $(\mathrm{M}=4.61 ; \mathrm{D} . \mathrm{T}=0.640)$ (ver Tabla 6).

Tabla 6. Estadísticos descriptivos aportación a la interpretación del vestuario escénico, profesorado-CPDA

\begin{tabular}{lccccc}
\hline & N & Mínimo & Máximo & Media & Desviación estándar \\
\hline Interpretación alumnos & 49 & 3 & 5 & 4.61 & .640 \\
\hline N válido (por lista) & 49 & & & & \\
\hline
\end{tabular}

Se realizó un análisis de frecuencias y los resultados determinaron que, ante la pregunta: “¿El vestuario escénico me ayuda a interpretar el personaje con mayor 
facilidad?", en una escala tipo Likert con 5 niveles de valoración (de 1/Nada a 5 / Mucho), el 69.40\% de los encuestados respondieron el nivel 5 (Mucho), $22.4 \%$ el nivel 4 (Bastante) y $8.2 \%$ el nivel 3 (Algo). Se observa, por tanto que, para el profesorado- CPDA, el vestuario es muy importante para facilitar la interpretación del personaje en la puesta en escena de las obras coreográficas (ver Tabla 7).

Tabla 7. Distribución de frecuencias respecto a la contribución del vestuario escénico a la interpretación, profesorado-CPDA

\begin{tabular}{lcc}
\hline & $\mathrm{N}$ & $\%$ \\
\hline Nada & 0 & 0.0 \\
Poco & 0 & 0.0 \\
Algo & 4 & 8.2 \\
Bastante & 11 & 22.4 \\
\hline Mucho & 34 & 69.4 \\
\hline Total & 49 & 100.0 \\
\hline
\end{tabular}

B) Análisis inferencial

Se comprobó la relación existente entre las diversas variables a través del análisis de tablas cruzadas. En primer lugar se relacionaron las variables género del profesorado- CPDA y la contribución del vestuario escénico a la interpretación.

En el caso masculino respondieron los 6 profesores encuestados, 4 consideraron que el vestuario escénico contribuía Mucho a facilitar la interpretación de los estudiantes, 1 Bastante, y 1 Algo. Ninguno de ellos contestó Nada o Poco.

En el caso femenino de las 43 profesoras encuestadas, 30 afirmaron que el vestuario escénico contribuía Mucho a facilitar la interpretación de los estudiantes, 10 Bastante, y 3 Algo. Nadie utilizó las respuestas Nada o Poco.

Respecto a la relación de género con el hecho de que el uso del vestuario escénico pueda facilitar la interpretación coreográfica, las pruebas de Chi cuadrado mostraron un $\mathrm{p}<.700$, donde 4 casillas $(66.7 \%)$ tenían un recuento menor que 5 , y la frecuencia mínima esperada era 0.49 , por lo tanto, no existían diferencias significativas entre las variables. Ambas eran independientes.

En el análisis de correlaciones bivariadas mediante el coeficiente de correlación de Pearson entre las variables experiencia del profesorado-CPDA y el hecho de que el vestuario escénico pueda facilitar la interpretación del alumnado, los resultados mostraron que la significatividad era 0.435 , por lo que no existía una asociación entre ambas. En consecuencia se realizó la d de Somers, y se comprobó que no existían diferencias significativas entre una variable y la otra, al mostrar una significatividad de 0.464 (>0.05).

Se verificó que, para el profesorado-CPDA, el vestuario escénico facilita la construcción de un rol o personaje en el contexto de una obra coreográfica con 
dramaturgia. El género y la experiencia profesional no determinaron la orientación de las respuestas, al ser variables independientes.

\section{Cuestionario para bailarines- $B N E$}

A) Análisis descriptivo

Se realizó un análisis descriptivo de la variable contribución del vestuario escénico a la interpretación de la danza, indicando los resultados que para las subdimensiones de la misma se observaron puntuaciones altas $(\mathrm{M}=4.39$; $\mathrm{DT}=.839)$, (ver Tabla 8).

Tabla 8. Estadísticos descriptivos importancia de los aspectos interpretativos, bailarines-BNE

\begin{tabular}{lccccc}
\hline & $\mathrm{N}$ & Mínimo & Máximo & Media & Desviación estándar \\
\hline $\begin{array}{l}\text { Interpretación } \\
\text { personaje }\end{array}$ & 23 & 3 & 5 & 4.39 & .839 \\
\hline
\end{tabular}

A continuación se expuso la frecuencia de esta variable. Respecto a la pregunta “¿El vestuario escénico me ayuda a meterme en el papel del personaje con mayor facilidad?" los resultados determinaron que en una escala tipo Likert con 5 niveles de valoración (de 1/Nada a $5 /$ Mucho), el 60.9\% de los bailarines encuestados señalaron el nivel 5 (Mucho), el $17.4 \%$ el nivel 4 (Bastante) y $21.7 \%$ el nivel 3 (Algo). Por tanto, para los bailarines-BNE, el vestuario es muy importante para facilitar la interpretación del personaje en la puesta en escena de las obras coreográficas (ver Tabla 9).

Tabla 9. Distribución de frecuencias respecto a que el vestuario contribuye a la interpretación del personaje, bailarines- $B N E$

\begin{tabular}{lcc}
\hline & N & $\%$ \\
\hline Nada & 0 & 0.0 \\
Poco & 0 & 0.0 \\
Algo & 5 & 21.7 \\
Bastante & 4 & 17.4 \\
\hline Mucho & 14 & 60.9 \\
\hline Total & 23 & 100.0 \\
\hline
\end{tabular}

\section{B) Análisis inferencial}

Se comprobó la relación existente entre las variables género e interpretación del personaje, a través del análisis de tablas cruzadas. En el caso masculino respondieron los 11 bailarines encuestados, 6 consideraron que la interpretación se facilita Mucho con el uso del vestuario escénico, 3 Bastante, 2 Algo, y ninguno de ellos contestó Poco o Nada. 
En el caso femenino, de las 12 bailarinas participantes, 8 afirmaron que la interpretación se facilitó Mucho con el uso del vestuario escénico, 1 Bastante y 3 Algo. Ninguna contestó Poco o Nada.

Respecto a la relación de género con el hecho de que el uso del vestuario escénico facilite la interpretación, la prueba de Chi cuadrado mostró un $\mathrm{p}<486$, donde 4 casillas $(66.7 \%)$ tenían un recuento menor que 5 y la frecuencia mínima esperada era 1.91, por lo tanto, no existían diferencias significativas entre las variables.

Se realizó un análisis de correlaciones bivariadas mediante el coeficiente de correlación de Pearson entre las variables experiencia de los Bailarines-BNE y la importancia del vestuario para la interpretación del personaje. Los resultados mostraron que la significatividad era 0.922 , por lo tanto no existía una asociación entre ambas. A continuación se realizó la d de Somers, y se constató que no existían diferencias significativas entre una variable y la otra, al mostrar una significatividad de $0.809(>0.05)$.

\section{Entrevistas y preguntas abiertas}

Respecto a la aportación que realiza el vestuario a la interpretación de la obra, se obtuvieron 13 referencias en el análisis realizado a través del software NVIVO 10, procedentes de las preguntas abiertas de los cuestionarios a bailarinesBNE y profesorado-CPDA, así como de las entrevistas realizadas a coreógrafos y personalidades de la danza.

A) Resultados en las preguntas abiertas

En las referencias que hacen los encuestados al tema de la contribución del vestuario escénico a la interpretación de la danza, se pudo constatar cómo, de forma unánime, se otorgó una gran relevancia al mismo ratificando los resultados cuantitativos.

\section{Profesorado-CPDA}

Se obtuvieron las siguientes opiniones:

- Belén (2017): "El vestuario ayuda al interprete/bailarín (alumno/a) en su actitud escénica, en su presencia y también les da la oportunidad de mostrar su disciplina dándole a la danza la seriedad e importancia que esta se merece".

- Rita (2017): "Considero que el vestuario tiene un papel muy importante porque de su diseño y elaboración el alumno aprende a contextualizar y a dar forma a una determinada época, o por el contrario a un personaje".

- Paz (2017): El vestuario debe ser una segunda piel para el bailarín/a, bailaor/a, ciertamente se gana en Interpretación y belleza estética cuando se acompaña de un buen vestuario, y es una parte importante de lo queramos hacer llegar al público, por 
su color, diseño. El vestuario dice muchas cosas. Lo creo fundamental para una buena puesta en escena.

- Zoe (2017): "Es necesario y delimita la obra en su estética, carácter y movilidad del intérprete".

- Abril (2017): "Comienzo a trabajar las sensaciones y la parte interpretativa desde el minuto uno para que a la vez que se van creando los aspectos técnicos se les va dando la intención y la fuerza que cada escena requiere".

- Inma (2017): "Creo que el vestuario facilita enormemente al alumnado a la transformación e interiorización del personaje, así como la interpretación y la expresividad, considero que un vestuario adecuado les hace sentir bien y proporciona seguridad".

- Leia (2017): "El vestuario escénico ayuda a los bailarines a meterse en el papel de un personaje y al público a transportarlo al contexto de la obra".

\section{Bailarines BNE}

- Rita (2017): "Cada vestuario da vida a un personaje en la obra, por muy secundario que sea, le dota de personalidad en una obra con dramaturgia".

\section{B) Resultados en las entrevistas}

Se realizó la siguiente pregunta a todos los entrevistados: "Cómo bailarín, ¿qué sensaciones le aporta el vestuario? ¿Le preocupa su elección y particularidades en cada personaje?". Se extrajeron las siguientes respuestas en las que los entrevistados coincidieron en mostrar sus inquietudes acerca del uso del vestuario escénico y su elección:

- Canales (2016): Muchísimo. El bailarín hay que vestirlo para que él se sienta lo más cómodo posible, lo más brillante posible, eso le da un carácter muy importante; o si está haciendo de feo, lo más feo posible, lo mejor posible pero lo que esté haciendo que esté muy adaptado a que se sienta bien y sea como parte de su cuerpo. Yo normalmente cuando diseño algo, mucho antes de debutar ya lo usamos, no me gusta estrenarlo el día del debut. Me gusta que la ropa ya esté usada, que la ropa esté hecha a tu cuerpo.

- Najarro (2017):Por supuesto, claro. Muchas veces estás ensayando algo muy complejo que te ha costado muchísimo, y de repente te visten para hacer eso, y se te cae el alma a los pies pues te imaginabas que ibas a ir vestido de otra manera. En otras ocasiones ocurre al revés, te han puesto piezas de vestuario que te han llenado mucho. Para mí es muy importante que el bailarín se sienta, ya no guapa o guapo, sino que sienta que lo que lleva acompaña a lo que va a interpretar. Es muy importante, que te 
mires al espejo y sientas que todo va acorde con lo que estás haciendo y que formas parte de un espectáculo, también por cómo vas vestido.

- Mata (2017) afirmó: "Por supuesto, debe hacerte sentir que eres ese personaje".

- Olmo (2017): Sí, a mí me preocupa. De hecho en “Ángeles Caídos", me llamó Antonio Najarro para hacer un papel concreto, el vuelo del ángel caído, basado en un personaje que yo hice en mi compañía que era el Ave Fénix. Entonces yo lo que hablé con él era que sí, que lo iba a hacer, pero que yo necesitaba para hacerlo, no un mantón normal, sino un mantón de piano del siglo XVIII. Teniendo eso lo hacía, pero que, si me ponían un mantón normal, no más caro, ni menos caro, sino de dimensiones normales, no podría, porque yo el vuelo tenía que hacerlo con un mantón así. Me daba igual que pesara 10 kilos, fíjate que además tiene un peso enorme, que se me abrió hasta una costilla en los ensayos, o sea que tiene un peso que realmente cuesta mucho bailar con eso, pero te da el personaje, te da ese vuelo del ángel que necesitábamos.

\section{DISGUSIÓN Y CONGLUSIONES}

El objetivo de este trabajo ha sido constatar la importancia del vestuario teatral en la puesta en escena de la Danza Española como elemento de comunicación y reconocer, en la simbología del vestuario escénico, referencias a la interpretación del personaje.

Como hipótesis de partida se esperaba que el vestuario escénico se considerara como un elemento más de la escenografía por parte de los distintos colectivos implicados en la puesta en escena de proyectos coreográficos, y por otro lado, se especulaba con que el uso del vestuario teatral facilitara la interpretación, atendiendo a su carácter simbólico.

En primer lugar, se ha tenido en cuenta la idea abordada por Hellín que defiende "la teoría semiótica como camino metodológico y conceptual que completa la Teoría del Análisis Coreográfico ya existente" (Hellín 2016, p.44). Desde esta perspectiva se ha conformado el presente trabajo con la dificultad que supone las escasas publicaciones existentes relacionadas con el tema del vestuario escénico en la danza, opinión compartida por Roldán quien afirma que "pocas publicaciones abordan, sin embargo, la evolución de la indumentaria teatral como elemento integrado en la puesta en escena, al contrario de lo que sucede, por ejemplo, con la historia de la escenografía, que cuenta con abundante bibliografía" (Roldán 2017, p.13). Igualmente se integra en el estudio la opinión general vertida por Martínez (2009) en su publicación "El Traje de Flamenca", respecto al carácter simbólico del traje y su función comunicadora, así como la idea expresada por Nieva, quien afirma que: "Las características principales del traje teatral no son sólo formas, color 
y exactitud cronológica o fantástica interpretación subjetivista, sino algo más: ese "algo más" es lo que hace del traje de teatro un elemento preponderante de la puesta en escena"(Nieva,2000,p.147).

Partiendo de estas premisas se articulan los resultados cuantitativos y cualitativos obtenidos y se observa un elevado índice de coherencia entre la percepción de los bailarines-BNE, el profesorado-CPDA, y los coreógrafos y bailarines de reconocido prestigio entrevistados. Al analizar los resultados en función de las respuestas de los diferentes colectivos, se ha pretendido constatar si el género y la experiencia profesional han influido en su opinión respecto a las variables identificadas. Al finalizar los análisis estadísticos se puede concluir que el género del profesoradoCPDA y de los bailarines-BNE, así como su experiencia profesional, no modifican los resultados obtenidos. En definitiva, estas dos variables respecto a importancia del vestuario y aportación a la interpretación son independientes y no se asocian de ninguna forma.

Para el análisis cualitativo se comenzó valorando si el profesorado, los bailarines y los coreógrafos y personalidades de la danza, apoyaban de forma global las hipótesis formuladas. Concluimos que, en todos los casos, los resultados cualitativos ratifican los resultados cuantitativos.

Como conclusiones generales podemos afirmar que, respecto al Objetivo 1 relativo a la importancia del vestuario escénico como elemento de comunicación, los resultados cuantitativos son muy similares entre el profesorado-CPDA y los bailarines-BNE. Predomina la idea casi unánime de que el vestuario es muy importante en las representaciones escénicas en general y, en la Danza Española en particular. En cuanto a los resultados cualitativos, se indica mayoritariamente la importancia del vestuario teatral como elemento integrador de la escena, enfatizando los resultados obtenidos con anterioridad. Se constata que la importancia que se da al vestuario teatral como transmisor de un mensaje es fundamental, tanto en el ámbito educativo como en el profesional.

En cuanto al Objetivo 2, relativo a la simbología del vestuario escénico y su aportación a la interpretación, se han tenido en consideración las opiniones de autores del ámbito teatral, como es el caso de Pellettieri (1996), quien determina que, en el ámbito de las artes escénicas, el diseño de un vestuario está íntimamente ligado al diseño del personaje, pues ayuda a construirlo y a contextualizarlo en el tiempo y el espacio, o Stanislavsky (2009), que subraya la importancia de la caracterización a través de la indumentaria para el momento de componer el personaje. Estas ideas son extrapolables al campo dancístico en las obras con dramaturgia, en las que el bailarín tiene el cometido de construir un personaje. Atendiendo a estas consideraciones se articulan los datos cuantitativos, y se observa cómo se obtienen resultados casi idénticos entre el profesorado-CPDA y los bailarines-BNE, teniendo en cuenta que ambos colectivos dan Mucha importancia a la aportación que el vestuario escénico hace a la Interpretación de la Danza. Respecto a los resultados cualitativos, 
se obtienen referencias que ratifican los resultados cuantitativos al destacar el carácter simbólico del vestuario escénico, aportando información fundamental para la interpretación de la obra. Se puede afirmar, por tanto, que el traje escénico se convierte en una potente herramienta gestual, ligada a lo visual, para el intérprete, en la representación coreográfica de la Danza Española. Se pone de manifiesto que, desde cualquier ámbito de la danza, profesional o educativo, se ha de tener en cuenta este carácter simbólico del vestuario teatral.

Para terminar, podemos concluir que se han cumplido las hipótesis planteadas. Los resultados obtenidos pueden contribuir a desarrollar otras líneas de investigación conducentes a profundizar en el análisis semiótico de una representación de danza desde todos sus elementos escénicos, tanto desde una perspectiva profesional como educativa de la danza.

\section{REFERENCIAS}

Arranz del Barrio, Ángeles A. (2016). Procesos metodológicos para la puesta en escena del repertorio tradicional en la Danza Española de Género Escénico. En S. Cometa (Ed). La investigación en Danza 2016, volumen 1. Valencia: Mahali, p. 108.

Bonilla, Luis (1964). La danza en el mito y en la historia. Madrid: Biblioteca Nueva.

Campo-Redondo, María y Labarca, Catalina. (2009). La teoría fundamentada en el estudio empírico de las representaciones sociales, un caso sobre el rol orientador del docente. Opción: Revista de Ciencias Humanas y Sociales, n. 60, pp. 47-48.

García, Chus (2009). Regiduría de vestuario del Ballet Nacional de España. En El vestuario en el Ballet Nacional de España. Madrid: Ministerio de Cultura, pp. 56-59.

Declaración de Helsinki de la AMM "Principios éticos para las investigaciones médicas en seres humanos" (2013).

Denzin, Norman K. (1970). Sociological Methods: a Source Book. Chicago: Aldin Publishing Company.

Eco, Umberto (1986). La estructura de lo ausente. Barcelona: Lumen.

Hellín, Inés (2016). La danza española y la narrativa escénica. Madrid: Publicaciones de la ADE.

Martínez, Rosa M. (2009). El traje de Flamenca. Sevilla: Signatura.

Marrero, Vicente (1959). El enigma de España en la Danza Española. Madrid: Biblioteca del Pensamiento Actual.

Ministerio de Educación Cultura y Deporte (2003). Ballet Nacional de España: 25 años. Madrid: Ministerio de Educación Cultura y Deporte.

Nieva, Francisco (2000). Tratado de escenografía. Madrid: Fundamentos Colección Arte. 
Orden de 9 de diciembre de 1997 por la que se establece el currículo del Grado Medio de Danza. BOE n ${ }^{\circ}$ 306, Madrid, 23 de diciembre de 1997.

Pelletteri, Osvaldo (Ed.) (1996). El teatro y sus claves: estudios sobre teatro argentino e iberoamericano. Buenos Aires: Galerna.

Roldán, María S. (2017). El diseño de vestuario teatral: de Buontalenti a Diaghilev. Madrid: Síntesis.

Sánchez-Contador, Amaya (2016). La identidad a través de la moda. Revista de Humanidades, n. 29, pp.131-152. DOI: https://doi.org/10.5944/rdh.29.2016.17220

Sierra, Restituto (2001). Técnicas de investigación social. Teoría y ejercicios. Madrid: Paraninfo Thomson Learning.

Sierra, Restituto (2007). Tesis Doctorales y trabajos de investigación cientifica. Madrid: Paraninfo Thomson Learning.

Stanislavski, Konstantín (2009). El trabajo del actor sobre sí mismo en el proceso creador de la encarnación. Barcelona: Alba. 